\title{
Design Improvement of Y-TZP Three Unit Bridges by Predicted Stress Concentration Using FEA and Experimental Failure Modes after Three Point Bending Test
}

\author{
ADRIAN ALMASI ${ }^{1}$, IULIAN ANTO NIAC ${ }^{2}$, SERGIU FOCSANEANU², MARIUS MANOLE ${ }^{3 *}$, ROBERT CIOCOIU², OCTAVIAN TRANTE $^{2}$, \\ KAMEL EARAR ${ }^{4}$, ADRIANA SACELEANU ${ }^{5}$, ANCA PORUMB ${ }^{1}$, CRISTIAN RATIU ${ }^{1}$ \\ 'University of Oradea, Faculty of Medicine and Pharmacy, 10,1 Decembrie Sq.,Oradea, Romania \\ ${ }^{2}$ University Politehnica of Bucharest, Faculty of Materials Science and Engineering, 313 Independentei Str., 060042, Bucharest, \\ Romania \\ ${ }^{3}$ Iuliu Hatieganu University of Medicine and Pharmacy, Department of Dental Propaedeutics and Esthetics, 8 Victor Babes Str., \\ 400012, Cluj Napoca, Romania \\ ${ }^{4}$ Dunarea de Jos University of Galati, Medicine and Pharmacy Faculty, Departament of Dentistry, 47 Domneasca Str., \\ 800008,Galati,Romania. \\ 5University Lucian Blaga Sibiu, Faculty of Medicine, 2A Lucian Blaga Str., 550169, Sibiu, Romania
}

\begin{abstract}
In this study an attempt to improve a three unit partial denture design is presented by performing experimental trials to find the failure load of a Y-TZP dental infrastructure. The experimental results are linked with FEA predictions to explain failure and find the optimum design. The test samples used were three unit fixed partial dentures obtained by CAD/CAM using as starting point a clinical case. Design improvement attempt was to increase connector cross-section size and modify its shape. Four samples with circular and elliptical connector cross-sections and $5 \mathrm{~mm}^{2}$ and $9 \mathrm{~mm}^{2}$ area were tested in flexure. The models created for CAM were used to perform FEA and find the stress distribution, pinpoint the stress concentrators and link the results to experimental failure modes. The results showed that connector design plays an important role in restoration success and increasing connector cross-section area the stress is distributed in a uniform manner. It was concluded that increasing connector cross-section area and using a wider shape (ellipse) strongly decreases failure probability.
\end{abstract}

Keywords: zirconia, dental bridge, finite element analysis, design, ceramic

In recent years zirconia has become a viable alternative to metal-ceramic restorations. Material and CAD/CAM technology progress yield high strength full ceramic restorations with high dimensional precision by standardized manufacturing possibilities and low costs [1, 2].

While the majority of patients prefer all ceramic crown restorations mainly due to good aesthetics, zirconia has other advantages: it is chemically durable, biocompatible and offers good mechanical characteristics [3].

The yttria - stabilized tetragonal zirconia polycrystal or Y-TZP became the most used zirconia type material in dentistry given its outstanding mechanical characteristics determined in static tests and has been used for a wide range of applications: endodontic posts, implant abutments, substructures for crowns, fixed dental prosthesis and implants.

The relevance of the inert ceramics for medical applications is important not just for dental medicine [46], but also for other clinical specializations [ 7-13].

Mechanical properties of dental materials alone are partly responsible for a successful restoration, structure design being equally important. In its normal usage the framew ork is heavily stressed in the oral environment, loads varying from $400 \mathrm{~N}$ up to $800 \mathrm{~N}$ during bruxism with usual masticatory loads ranging from 500 to $600 \mathrm{~N}$.

Unlike removable dentures, crowns and bridges are cemented and can be removed and studied only by the dentist making periodic inspection (which could increase the working life) difficult. Since the human tooth geometry is very intricate, with low symmetry, CAD/CAM technology is required for high dimensional accuracy and best fit for patient oral physiology. Following the three main steps: digital data acquisition, computer processing/design and structure fabrication a reliable product can be obtained.

A three unit bridge is a dental device used as an alternative for an implant. It consists on a false tooth connected to two caps placed over the adjacent healthy teeth. This configuration implies mainly a bending stress on the connectors, with a tensile component in the gingival region and compressive in the occlusal.

The design governs load distribution and magnitude and, based upon this information, fracture location can be predicted and preventive actions undertaken. The connector region requires particular properties given mastication biomechanics, esthetics and load distribution [14].

The load at failure determined experimentally on single tooth and three or four units varies from $700 \mathrm{~N}$ up to $4100 \mathrm{~N}$ [15-17], such variation being explained by not using standardized tests and measurement methods. Such tests, performed on as sintered materials, are not really revealing for the in vivo case, where ageing of zirconia by mechanical stresses and saliva contact have detrimental effects on its mechanical behavior [18].

Since CAD technology is used in framework design, performing a finite element analysis (FEA) is an efficient method to study and optimize load distribution and indentifying stress concentrators to ensure longer working life.

The finite element method is numeric and it is used to study stresses and deformation in structures. Although subjected to various factors which influence its accuracy, it is an efficient alternative to engineering techniques such as photoelasticity and interferometry. 
In this study an attempt to increase the strength of $Y$ TZP three element dentures with using various connector designs, evaluate and correlate the stress distributions predicted by FEA with experimental tests failure modes is presented.

\section{Ecperimental part}

\section{Materials and methods}

Sample preparation

In this study yttria stabilized zirconia was used as restoration material and using CAD/CAM technology four unit bridges used for right lower molar replacement in a specific clinical case were manufactured.

The four samples were adaptations for the same missing tooth with connector cross-sections shape (circular and elliptical) and size ( 5 and $9 \mathrm{~mm}^{2}$ ) varied, as shown in figure 1.

The acquired patient digital data was used in a vhf CAM 4 - K4IMPRESSION machine to mill the physical samples which were sintered according to producer specifications.

The four samples were tested in flexure using a Walter+Bai LFV 300 universal testing machine equipped with a three point bending fixture. The tests were performed up to failure the samples being supported by custom made fixture.

Then digital models were converted to solids using FreeCAD software, imported in Dassault SolidWorks and using SolidWorks Simulation a FEA was performed and the results compared with the experiment.

\section{Flexure tests}

The tests were performed by simply placing the zirconia restoration on metallic supports and loading it in a three point bending configuration. No cement layer was used since it was aimed to determine the effective strength of the restorations with various connector designs. Including the cement layer an uncontrollable variable would be included: this layer is prepared and applied by hand thus thickness and composition would greatly affect assembly properties and loading condition.

Sample coding followed a simple protocol, in which the shape is specified by the capital letter $C$ for a circular cross- section and " $E$ " for an elliptical one, followed by the index 5 or 9 , signifying the area of 5 or $9 \mathrm{~mm}^{2}$.

In the test the material behaved in a brittle manner: the framework failed with no warning and any signs of plastic deformation.

The load -displacement curves shown in figure 2 reveal a two stage load transfer. First, the framew orks setting on the supports occurred -a slightload increase was observed in respect with the displacement. Further, the load was directly taken by the framework and distributed towards the supporting caps. The rigidity of the framework can be appreciated by studying the slope on this second region: the less rigid one, unexpectedly, was the one with an elliptical $5 \mathrm{~mm}^{2}$ connector, test sample ZE5.

Sample ZC9 and ZC5 have a similar rigidity, while the most rigid was sample ZE9.

The results obtained were somewhat surprising, the $5 \mathrm{~mm}^{2}$ elliptical connector framework failed at a lower force than the $5 \mathrm{~mm}^{2}$ circular connector framew ork, as observed in figure 3.

This result was quite intriguing: first thought was a large defect within the test sample which caused premature failure, but no such feature was clearly observed by fracture surface analysis.

Finding the cause for this unusual result was directed towards load transfer and stress concentrations study within the framework using finite element analysis (FEA).

\section{FEA setup and results}

Performing this analysis required the original stereolitography files (STL), sections shown in figure1, reducing their size by $25 \%$, because of contractions during sintering, remeshing and solid conversion for the study. The analysis was performed using Dassault Systems SolidWorks Simulation. The material library did not comprised any data for Y-TZP, thus, following a literature study, the material properties shown in table 1 were used. The tensile and yield strength were considered equal, since the material is brittle.

The restraints and loading conditions attempted to recreate the experimental setup: two fixed geometries were selected on the bottom of molar \#47 and premolar \#45 while the load was applied on the crest of the pontic,

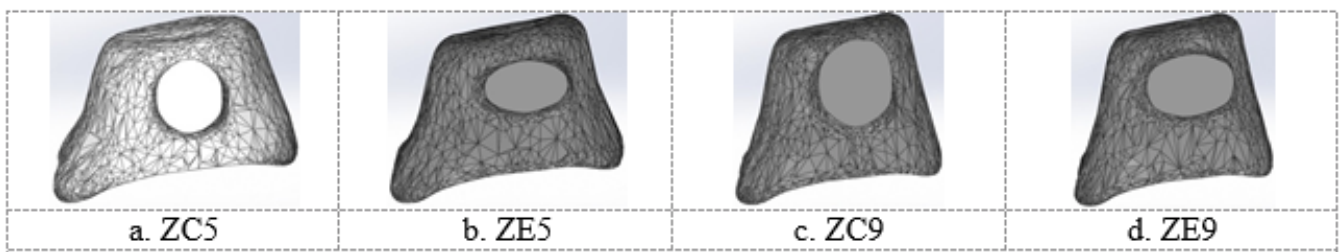

Fig. 1 The designed three unit bridge with various connector shape and size: a. circular and b. elliptical cross-section with a $5 \mathrm{~mm}^{2}$ area and $c$. and d., with a $9 \mathrm{~mm}^{2}$ (sections are not to scale)

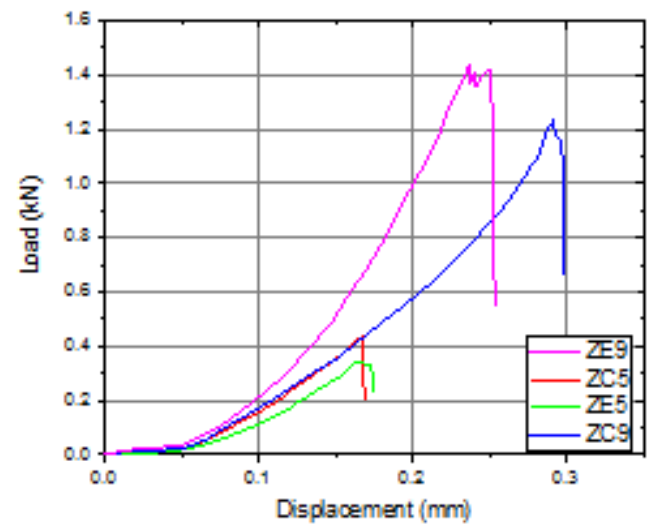

Fig. 2 Load -displacement curves for tested ensembles

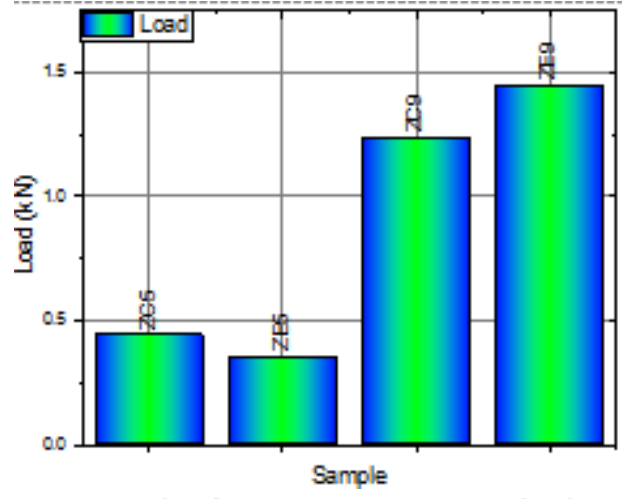

Fig. 3 Bar plot showing a comparison of load at failure 
Table 1

Y-TZP MATERIAL PROPERTIES

\begin{tabular}{|c|c|}
\hline Property & Value \\
\hline Elastic Modulus & $200000\left[\mathrm{~N} / \mathrm{mm}^{2}\right]$ \\
\hline Poisson's Ratio & 0.3 \\
\hline Shear Modulus & $77000\left[\mathrm{~N} / \mathrm{mm}^{2}\right]$ \\
\hline Mass Density & $6050\left[\mathrm{~kg} / \mathrm{m}^{3}\right]$ \\
\hline Tensile Strength & $500\left[\mathrm{~N} / \mathrm{mm}^{2}\right]$ \\
\hline Compressive Strength & $2000\left[\mathrm{~N} / \mathrm{mm}^{2}\right]$ \\
\hline Yield Strength [Ys] & $750\left[\mathrm{~N} / \mathrm{mm}^{2}\right]$ \\
\hline Thermal Expansion Coefficient & $1.05 \mathrm{e}-005[1 / \mathrm{K}]$ \\
\hline Thermal Conductivity & $0.2256[\mathrm{~W} /(\mathrm{m} \cdot \mathrm{K})]$ \\
\hline Specific Heat & $1386[\mathrm{~J} /(\mathrm{kg} \cdot \mathrm{K})]$ \\
\hline
\end{tabular}

as shown in fig. 4. A 500N load was applied, Apholt et al [18] suggesting that fixed partial dentures should withstand forces of 400N in the anterior and $600 \mathrm{~N}$ in the posterior region. According to Nishigawa et al. [19] the maximum bite force associated with sleep bruxism exceeds $800 \mathrm{~N}$.

This scenario was considered as worst case scenario of loading during a bite, the load applied locally, outwards, creating a moment in the connector region and on the surface of the caps the load was unevenly distributed.

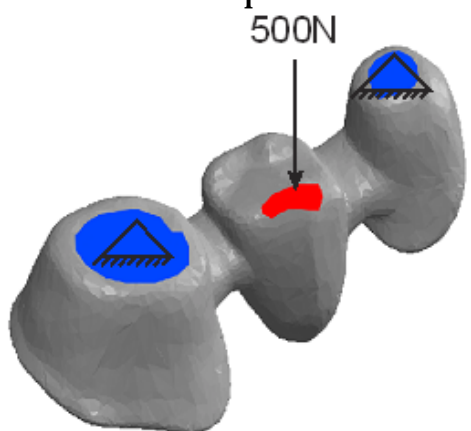

Fig. 4 Loading scenario: bottom of the two copings restrained by a fixed geometry and the load applied on the crest of the pontic- similar with experimental loading

Post analysis captions are shown in following paragraphs. A supplementary analysis was performed by probing on the exterior (labeled as Top) and the interior surface (labeled as Bottom) of the loaded ensembles to compare the von Misses stresses.

The study performed on the ZC5 model concluded that the framework would fail in a $500 \mathrm{~N}$ loading scenario, as the von Misses stresses shown in figure $5 b$ suggest.
Using a circular cross section connector with a $5 \mathrm{~mm}^{2}$ area appears to be a poor decision when a strong bite takes place. The load is unevenly distributed, high stress concentrators appear at the transition from the top to the side wall of the cap. This region acts as a favorable crack nucleation site causing premature failure. As for the connectors themselves, a significant amount of load is distributed where the connector joins the cap, but the stresses are below the yield strength of the material.

In this configuration the failure would most likely occur on the tooth \#45 cap, followed by a high probability to fail in the region where the connector joins the cap.

Using a $5 \mathrm{~mm}^{2}$ elliptical connector yielded higher stresses and higher failure probability than a $5 \mathrm{~mm}^{2}$ circular connector, as observed in the experimental study. The stress distribution shown in fig. $6 \mathrm{~b}$ reveals higher magnitudes with the elliptical connector in critical regions.

Increasing the bearing surface of the connector by modifying the geometry has an immediate effect also on load distribution. The stresses on the connector region are slightly increased when compared with the previous case, ZC5, suggesting a more efficient load transfer in the framework. An interesting fact is the stress concentration which occurs on the tooth \#45 at the joining of the roof with the side wall of the reconstruction. The transition in this region appears steeper than that of ZC5. The cause of this design flaw is a consequence of processing route. The patient dental configuration is scanned and the reconstruction is generated using a specific algorithm which establishes best geometry with acceptable safety factors. Forcing a connector cross-section change, material is added or removed in order to compensate and maintain a constant volume for the given shape. This unpredictable addition or subtraction creates regions with sharp edges which act as stress concentrators, as identified in this case.Increasing the connector surface to $9 \mathrm{~mm}^{2}$ has an obvious influence, as show $\mathrm{n}$ first in the results performed on sample ZC9, shown in figure 7 .

Increasing the transverse surface area of the connector the load is evenly distributed, slight stress concentrations can be observed at the joining of the connector with the

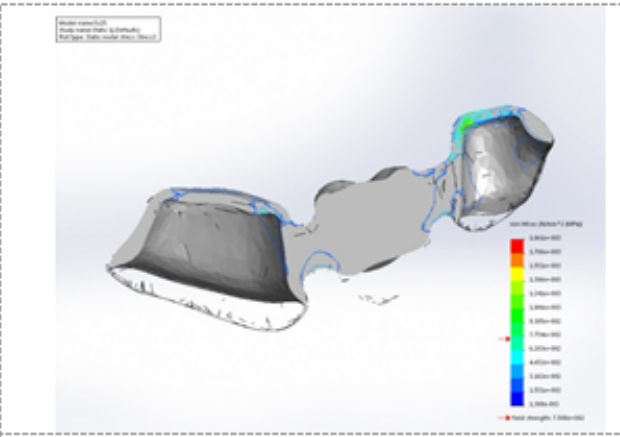

a. Von Misses stress distribution in section

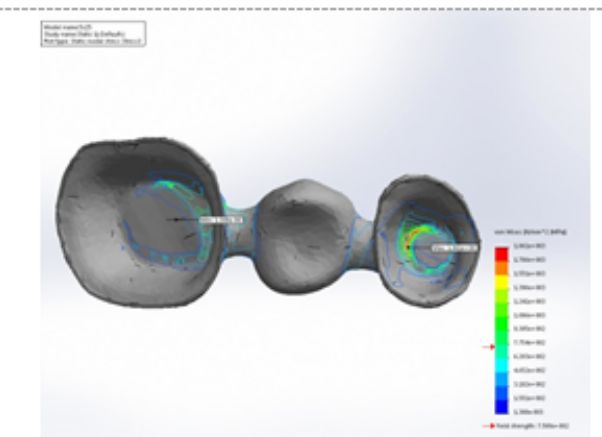

c. Von Misses stress distribution on backplane

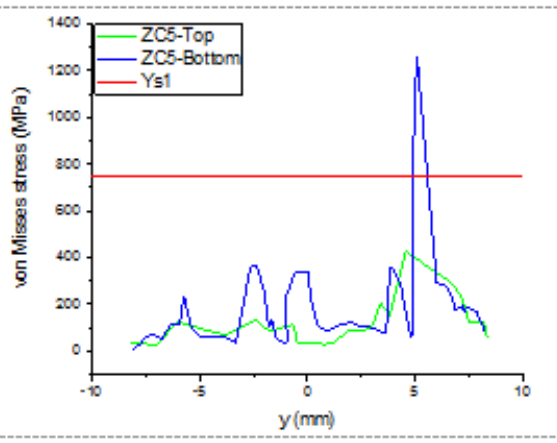

b. Von Misses stress distribution on superior and inferior region of the framework

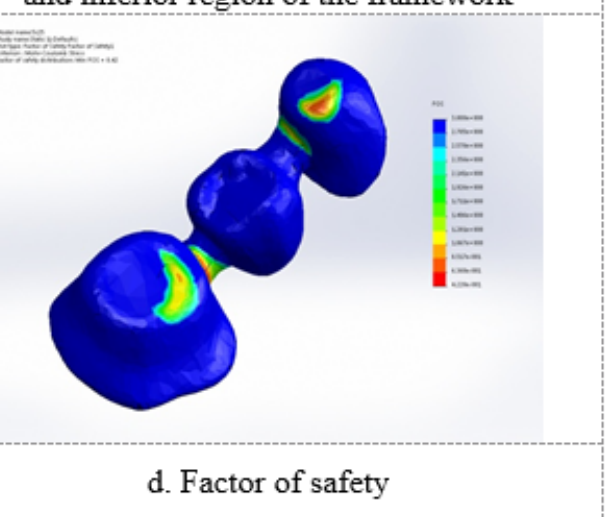

Fig. 5 Simulation results on the ZC5 model: a.Von Misses stress distribution in section; b.Von Misses stress distribution on superior and inferior region of the framework; c.Von Misses stress distribution on backplane; d.Factor of safety 


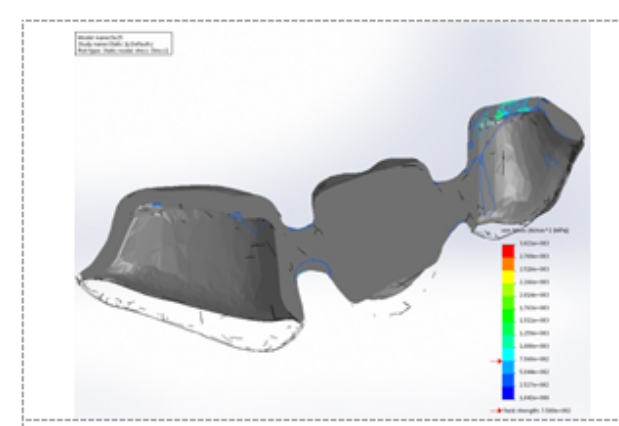

a. Von Misses stress distribution in section

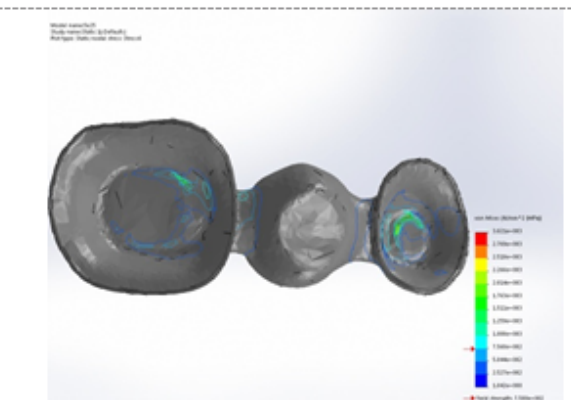

c. Von Misses stress distribution on backplane

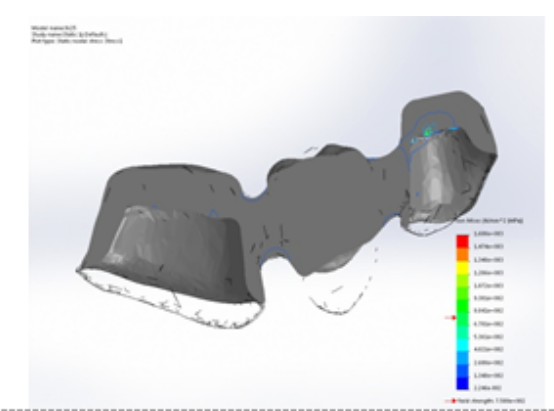

a. Von Misses stress distribution in section

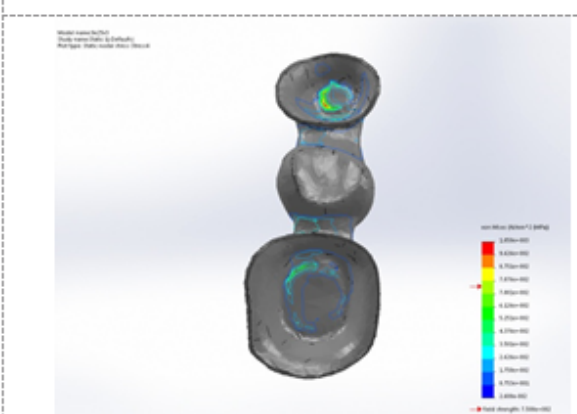

c. Von Misses stress distribution on backplane

cap, but these stresses are $1 / 3$ of the yield strength of the material. A peak stress was observed, again, at the joint between the roof and side wall of the cap. The stress was concentrated at the transition between two mesh elements and its intensity could have been lowered by using a finer mesh. Still, this clearly shows that the joint of the two elements is a weak spot in the structural integrity of the framew ork.

Results of the study performed on the ZE9 model are shown in figure 8.

Using an elliptical cross-section reduces the stresses within the framework since the load distribution is more favorable. Again, stress concentrators appear in the same region, where the roof joins the side wall of the same tooth as in all previous cases. This aspect is a strong indication that, during teeth preparation for the framework, a flat,
Fig. 6 Simulation results on the ZE5 model: a.Von Misses stress

distribution in section; b.Von Misses stress distribution on superior and inferior region of the framework; c.Von Misses stress distribution on back-plane;

d. Factor of safety
Fig. 7 Simulation results on the ZC9 model: a.Von Misses stress distribution in section; b.Von Misses stress distribution on superior and inferior region of the framework; c.Von Misses stress distribution on back-plane; d. Factor of safety 


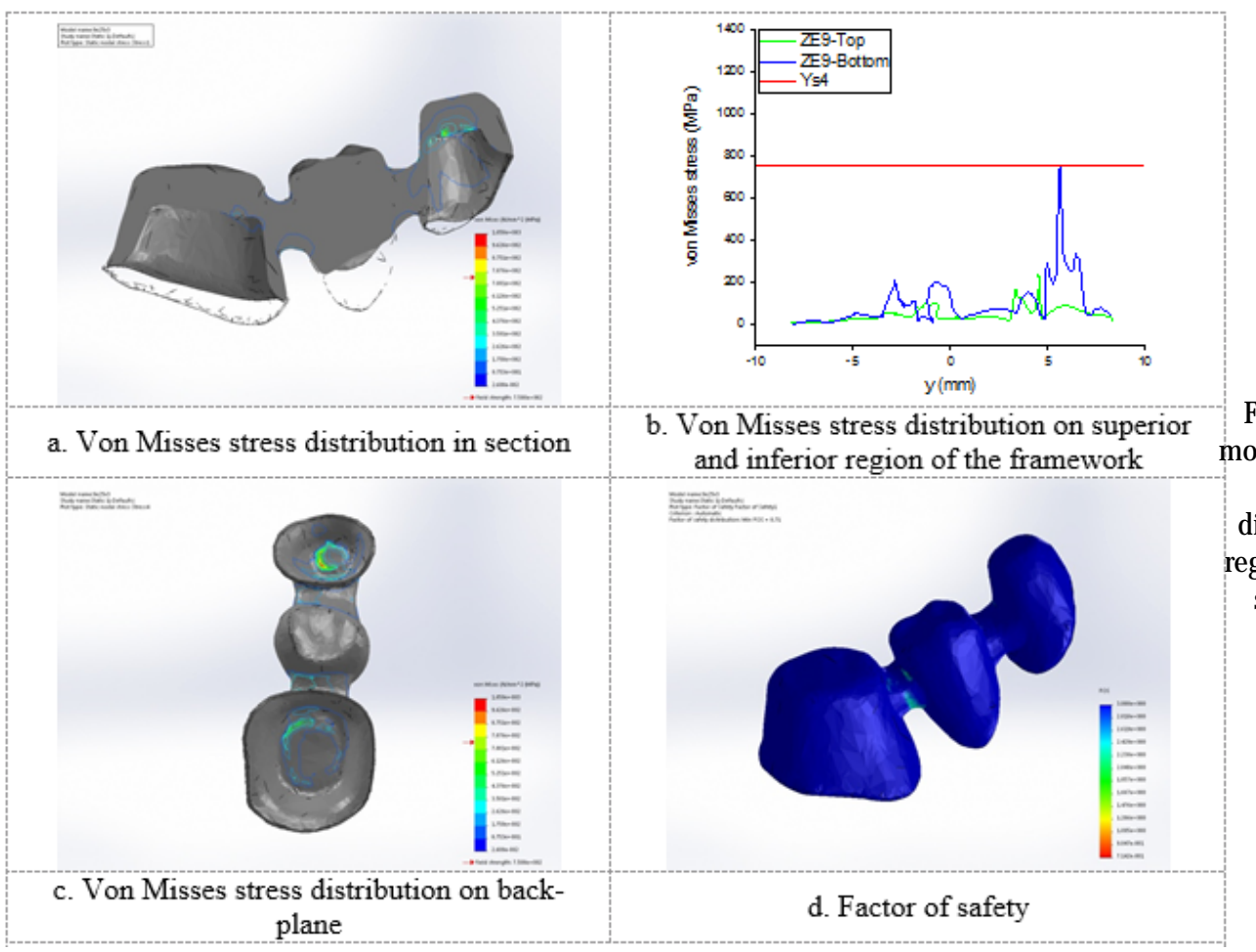

Fig. 8 Simulation results on the ZE9 model: a.Von Misses stress distribution in section; b.Von Misses stress distribution on superior and inferior region of the framework; c.Von Misses stress distribution on back-plane; d.Factor of safety

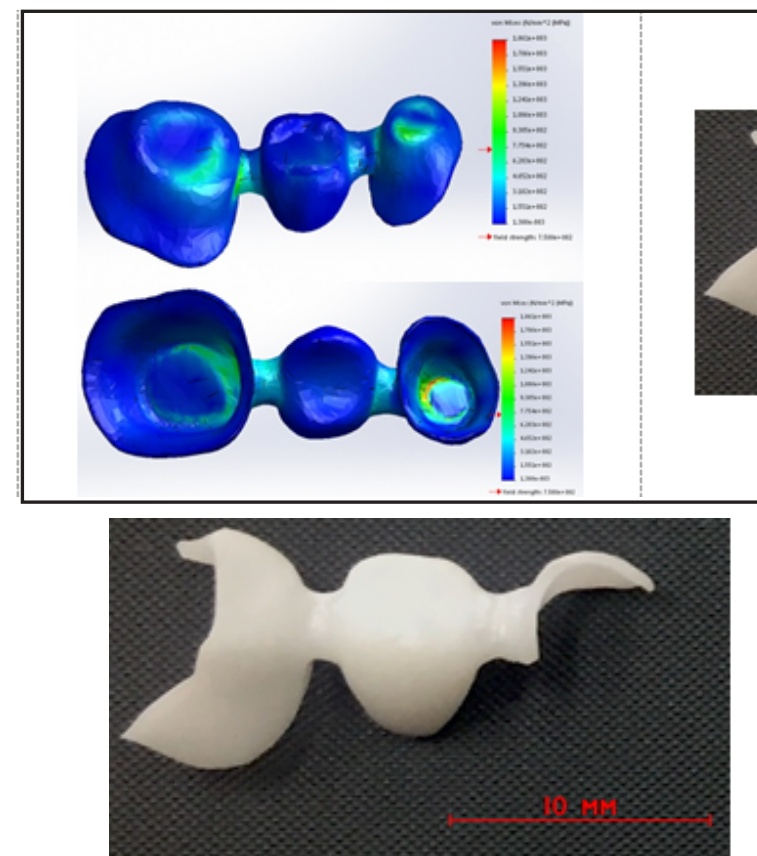

Fig. 10 Failure mode of the framework with $5 \mathrm{~mm}^{2}$ circular crossection

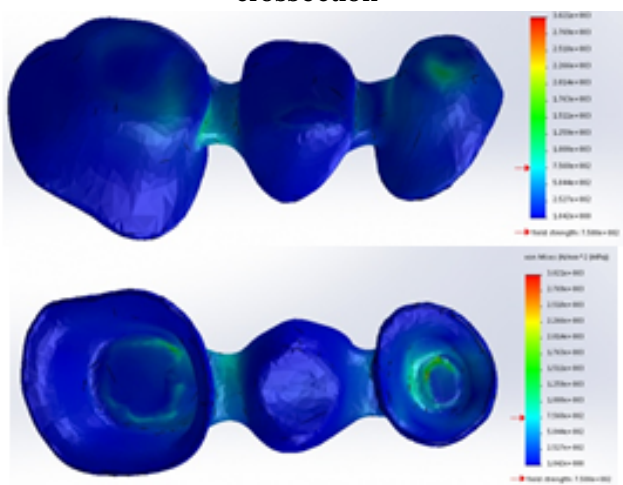

Fig. 11 Von Misses stress distribution in ZE5 model

restoration in the setup and modified the stress distribution, explaining the fracture in the median region of the tooth \#47.
A good match appears with model ZE5, the stress concentrators and failure patterns are shown in figure 11 and figure 12.

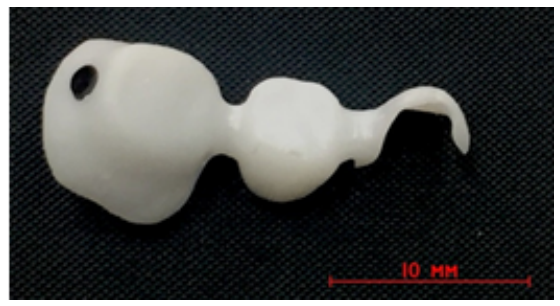

Fig. 12 Failure mode of the framework with $5 \mathrm{~mm}^{2}$ ellliptical crossection

In a $5 \mathrm{~mm}^{2}$ elliptical cross-section the stresses were concentrated mainly on the tooth \#45, the values rising well above the yield strength of the zirconia. The stress distribution resembles with the failure pattern. The origin was located where the roof joins the side wall of the restoration, while the crack path followed the stresses predicted by the simulation

Increasing the cross-section to $9 \mathrm{~mm}^{2}$ the stresses are more evenly distributed, as shown in figure 13, higher values can be observed in the same location, where the roof joins the wall of the restoration on tooth\#45. Excepting this region, the stress values fall under the yield strength of the zirconia, 750MPa.

The origin of the failure, observed in figure 14 , coincides, again, with the region with highest stresses. 


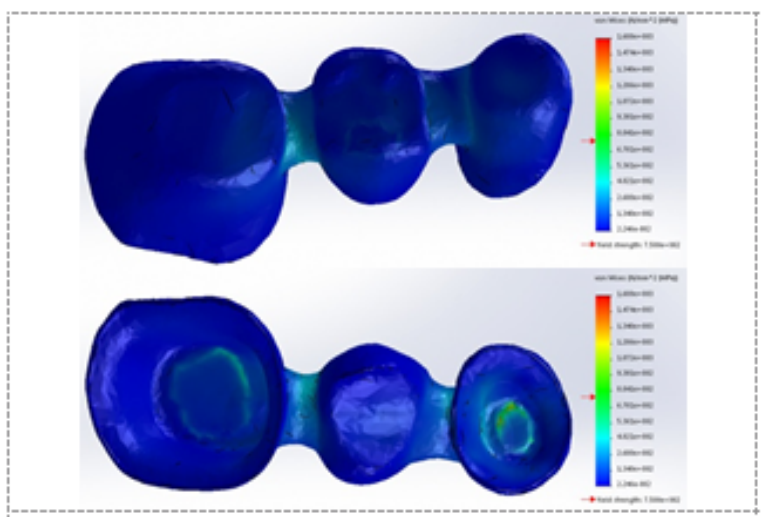

Fig. 13 Von Misses stress distribution in ZC9 model

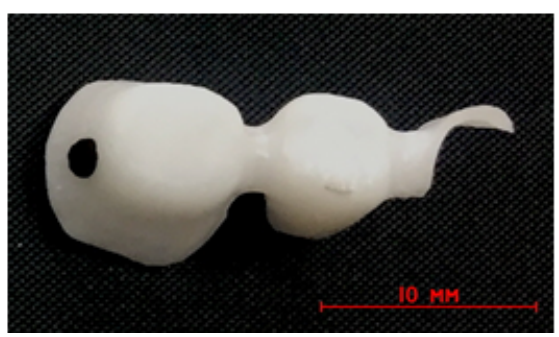

Fig. 14 Failure mode of the framework with $9 \mathrm{~mm}^{2}$ circular crossection

With an elliptical connector cross-section the load distribution is more even on the supporting surface, as the plot from figure 15 shows. Stress concentrations appear in the same region as in all other samples, where the roof joins the side wall of the restoration. The observed failure was innitiated where the stresses reached the maximum value, the crack following the path from the high stress towards low stress region, following the joining line of the side wall and the roof, as presented in figure 16.

\section{Results and discussion}

The load distribution is clearly affected by connector cross-section shape and area. Using an elliptical crosssection the loads are more uniformly distributed in the entire framework, considerable lower on critical area, such as where the connector joins the cape and the roof of the cape where most of the loads are concentrated.

Apparently, according to current simulation results, 3 out the 4 frameworks would fail at a $500 \mathrm{~N}$ load. The experimental runs showed that both $5 \mathrm{~mm}^{2}$ restorations failed at loads inferior to $500 \mathrm{~N}$, while the $9 \mathrm{~mm}^{2}$ crosssection connector area frameworks failed at 3 times the load. Studying the stress concentrations and loads in the simulation we observed that the loads are localized, most likely at transitions between triangles used to define the geometry. In practice such sharp transitions would be less likely to occur because of CAM manufacturing tolerances. Still, the stress concentrations predicted by simulation coincided with the origin of the failure of the experimental samples and the load distribution around this region was exactly the path followed by the crack. Connector design is very important for restoration performance: an adequate thickness is required for efficient load bearing and stress concentrators (sharp edges) are to be avoided by designing rounded corners.

Similar studies [18, 20,21] show high stresses around the connector. In these studies the cement layer is taken into account: with a considerable lower elastic modulus than zirconia and the specific loading condition the stresses would exceed its yield strength and either it would plastically deform or fail thus creating different stress distributions in the monolithic zirconia [21]. Disregarding

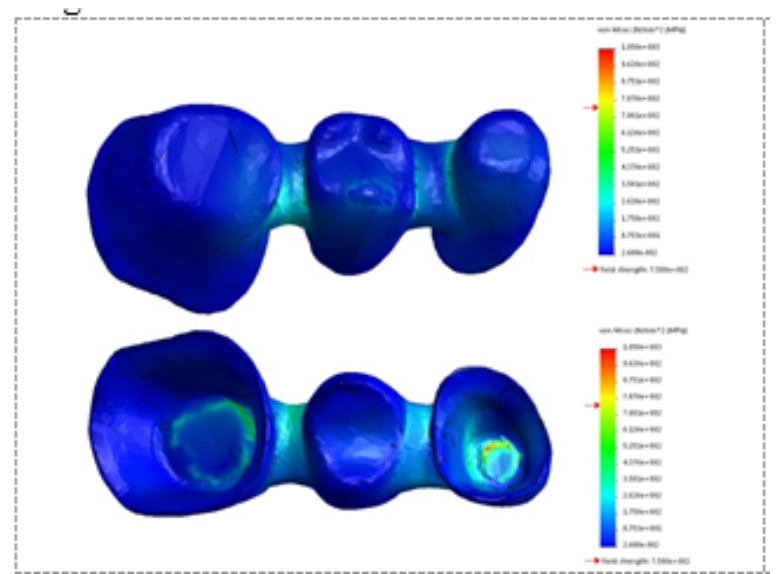

Fig. 15 Von Misses stress distribution in ZE9 model

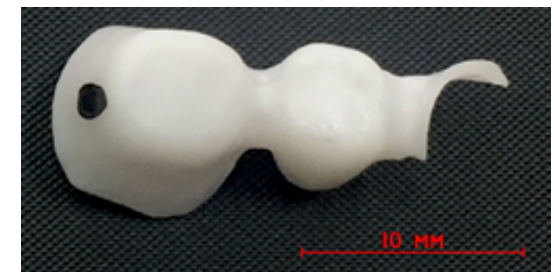

Fig. 16 Fallure mode of the framew ork with $9 \mathrm{~mm}^{2}$ elliptical crossection

the cement layer and considering a simple support the whole load taken by the framework, in these particular case stress concentrations appear where the roof joins the side wall of the restoration. Excepting these regions, indeed, the most stressed region is where the connector joins the exterior wall of the skirt, as other studies have shown.

In a study performed by Coreia et al. [22] it was mentioned that a titanium cantilever-fixed partial denture with $5.28 \mathrm{~mm}^{2}$ connector area is unable to support maximum mastication loads. In this case, using a two caps supported bridge, given a normal loading during mastication, the infrastructure would comply with mechanical requirements. Still, increasing connector area is strongly recommended, either by radical design change or by fillet/chamfer introduction.

It must be mentioned that this study has its limitations in respect to in vivo case. Also it pertains to a worst case loading scenario.

\section{Conclusion}

The material used for dental restoration alone does not grant success, infrastructure design plays also an important role. It was experimentally proven that increasing connector cross-section area enhances the load bearing capacity of the restoration and by FEA it was observed that stress distribution is more even. The failure would occur in the gingival area, where tensile stresses are present.

Another key factor would be preparation of the teeth which will act as anchors for the framework; it should be performed in such way that inclined surfaces and sharp angles are avoided, unless necessary. The CAD model for the framew ork should be inspected thoroughly to remove any features that could act as stress concentrators.

In this study using a wide section, an ellipse would be preferable, and increasing the connector cross-section area yielded the best results in what we considered to be worst loading case scenario.

Using the right restoration material and adapting the design for strength, aesthetics and functionality remains a difficult task. Y-TZP provides good mechanical characteristics and selecting an efficient design increases restoration working life. 


\section{References}

1. RAIGRODSKI A.J ., J Prosthet Dent., 92(6), 2004, p.557-562.

2. TINSCHERT J., NATT G., HASSENPFLUG S., et al., Int J Comput. Dent., 7(1), 2004, p.25-45.

3. POL-CHRISTIAN W.P., KALK W., Int. J. Prosthodont., 24(6), 2011, p.566-575.

4. CRACIUNESCU E., SINESCU C., NEGRUTIU M.L., et al., J Adhes Sci Technol., 30(6), 2016, p.666-676.

5. EARAR K., ANTONIAC I., BACIU S., et al., Rev. Chim. (Bucharest), 68, no.11, 2017, p. 2700-2703

6. ANTONIAC I., SINESCU C., ANTONIAC A., J Adhes Sci Technol., 30(16), 2016, p.1711-1715.

7. BENEA H., TOMOAIA G., SORITAU O., et al., Romanian Biotechnological Letters, 21(4), 2016, p.11720-11728.

8. ANTONIAC I., NEGRUSOIU M., MARDARE M., et al., Medicine. 96(19):e6687, 2017.

9. COSTACHE V., MOLDOVAN H., ARSENESCU C., et al., Minerva Cardioangiologica, 66(2), 2018, p.191-197.

10.MARINESCU R., ANTONIAC I., LAPTOIU D., et al, Mat. Plast., 52, no.3, 2015, p. 340-344.

11. GRECU D., ANTONIAC I., TRANTE 0., et al., Mat. Plast., 53, no.4, 2016, p.776-780.
12. CAVALU S., KAMEL E., LASLO V., et al., Rev. Chim (Bucharest), 68(12), 2017, p.2963-2966.

13. RIVIS M., PRICOP M., TALPOS S., et al., Rev. Chim. (Bucharest), 69, no.4, 2018, p.990-993.

14. MELLO C, SANTIAGO JUNIOR J.F., GALHANO G, et al., Int J Prosthodont., 29(2), 2016, p.157-160.

15. LUTHY H, FILSER F, LOEFFEL 0, et al., Dental Materials, 21(10), 2005, p.930-937.

16. TINSCHERT J, NATT G, MAUTSCH W, et al., Int J Prosthodont., 14(3), 2001, p.231-238.

17. SUNDH A, MOLIN M, SJ OGREN G., Dental Materials, 21(5), 2005, p.476-482.

18. APHOLT W, BINDL A, LÜTHY H, MORMANN WH., Dental Materials, 17(3), 2001, p.260-267.

19. NISHIGAWA K., BANDO E., NAKANO M.,J Oral Rehabil., 28(5), 2001, p.485-491.

20.THOMPSON M.C., THOMPSON K.M., SWAIN M., Aust.Dent.J ., 56(3), 2011, p.302-311.

21. HA S.., J.Adv Prosthodont, 7(6), 2015, p.475-483.

22. CORREIA A., FERNANDES] ., CAMPOS J ., etal., Rev. Odonto Ciencia, 24(4), 2009, p.420-425.

Manuscript received: 9.072018 